Case Reports
in Dermatology

\title{
Pilomatrixoma with Atypical Features: A Case Report
}

\author{
Meina Missak Aaron Haig Manal Gabril \\ Pathology and Laboratory Medicine, Schulich School of Medicine and Dentistry, \\ Western University, London, ON, Canada
}

\section{Keywords}

Pilomatrixoma · Atypical features · Pilomatrix carcinoma

\begin{abstract}
Pilomatrixoma is an uncommon, benign tumor with differentiation towards both the hair matrix and cells arising in the cortex, most frequently appearing in the first or second decade of life. In rare instances, pilomatrixomas can show malignant transformation. Pilomatrix carcinoma is extremely uncommon and has traditionally been considered a tumor of low malignant potential; however, a high local recurrence rate has been reported. There is a paucity of literature on these lesions, with only a few reports describing the spectrum of malignant changes seen in these lesions. In this case report, we present a case of pilomatrixoma in an adult patient showing atypical features. While the tumor is small, there are focal features that suggest progression to malignancy, but do not fulfill the criteria for pilomatrix carcinoma. These focal atypical features include a focal infiltrative pattern at the periphery, with a variable cytological atypia and an increased mitotic rate, up to five mitotic events/high-power field. Irregular foci of central necrosis (comedonecrosis) were present in several lobules. Some of the features identified were similar to a subset of pilomatrixoma, known as "proliferating pilomatrixoma." However, our case did not have the diffuse changes or larger size that has been frequently reported in "proliferating pilomatrixoma." In conclusion, given the lack of focality of the changes, the lesion in our case is best described as a pilomatricoma with atypical features. Furthermore, our case may highlight the need to ensure close clinical follow-up for these
\end{abstract}




\section{Case Reports in Dermatology}

Missak et al.: Pilomatrixoma with Atypical Features: A Case Report

lesions with unexpected atypical features that raise concern of recurrence and malignant transformation.

\section{Introduction}

Pilomatrixoma, also referred to as pilomatricoma or calcifying epithelioma of Malherbe, is an uncommon benign tumor with differentiation towards both the hair matrix and cells arising in the cortex [1]. Pilomatrixoma is classified within the family of skin adnexal tumors [1]. These tumors most frequently appear in the first or second decade of life. Pilomatrixoma occurs as a solitary lesion; however, multiple lesions and familial patterns have been reported. Hereditary types have been associated with myotonic dystrophy [2]. The lesions are typically painless, slow-growing, deep-seated hard subcutaneous nodules arising most commonly within the face and upper extremities [3]. In rare instances, pilomatrixomas can show malignant transformation. Pilomatrix carcinoma is extremely uncommon and has traditionally been considered as having a low malignant potentially; however, a high local recurrence rate has been reported [4]. In this report, we present a case of pilomatrixoma in an adult patient showing mild atypical features which do not fulfill the criteria for definitive carcinoma but raise the possibility of progression to malignancy.

\section{Case Report}

A 57-year-old man presented with a long history of a persistent, firm raised nodule in the right lumbar area with increasing size. Clinical impression was a sebaceous cyst. The patient was otherwise well, with no constitutional symptoms and no significant past medical history.

The specimen was composed of a nodule measuring $1.7 \times 0.9 \times 0.9 \mathrm{~cm}$ embedded in subcutaneous tissue with an overlying ellipse of unremarkable skin. Multiple sections of the excisional biopsy demonstrated nearly circumscribed growth of the basaloid lesion in dermis and subcutaneous fat tissue with a surrounding pseudocapsule (Fig. 1a). There was zonation between basaloid cells at the periphery with numerous "shadow" cells in a fibrocollagenous matrix with an inflammatory background (Fig. 1a). Numerous foci of keratin were evident, with an associated multinucleated giant cell reaction. The tumor exhibited focal atypical features, including very focal infiltrative pattern at the periphery (Fig. 1b). Irregular foci of central necrosis (comedonecrosis) were present in several lobules (Fig. 1c-d). Also, the tumor was composed predominantly of basaloid cells with a variable degree of atypia (Fig. 1d) and an increased mitotic rate, up to five mitotic events/high-power field (Fig. 1e). No definite vascular or lymphatic invasion was identified. The tumor was close to the surgical margins but appeared to have been completely excised. These features are consistent with noncalcified pilomatrixoma with atypical features.

\section{Discussion}

We report a challenging case of a pilomatrixoma, with atypical features but not diagnostic of definite carcinoma. The atypical features identified include minimal infiltrating margin,

\section{Karger'=}




\section{Case Reports in Dermatology}

Missak et al.: Pilomatrixoma with Atypical Features: A Case Report

focal cytological atypia of the basaloid cells with an increase in mitotic activity, and rare areas of necrosis. Also, in our case, the cellular portion is more predominant than shadow cells, which is an unusual feature for long-standing lesions [5]. The histological stages of pilomatrixoma are (1) early small cystic lesions, (2) fully developed large cystic lesions, (3) early regressive lesions with foci of basaloid cells and shadow cells with multinucleated giant cells, and (4) late regressive lesions with numerous shadow cells and less basaloid cell foci as well as presence of calcification and ossification [6].

However, the small size, lack of a marked infiltrative pattern, and absence of perineural and vascular invasion make it difficult to confirm a definitive diagnosis of malignancy. Furthermore, increased mitotic activity was noted which, while uncommon feature of pilomatrixoma, can be a marker for more aggressive biologic behavior [7].

Pilomatrix carcinoma is rare and may arise de novo without a pre-existing lesion or progress from benign lesions [8]. Histological features of malignancy include large tumor with nests of atypical basaloid cells, increase in mitotic activity, infiltrative border, and lymphovascular invasion. Areas of necrosis are also common [8].

Kaddu et al. [9] described a subset of pilomatrixoma known as proliferating pilomatrixoma with histological architectural features different from those of usual pilomatrixoma. These tumors have large size and are found mainly on the head and neck. Histologically, these tumors showed relatively large lesions predominantly composed of a lobular proliferation of basaloid cells, exhibiting variable nuclear atypia and mitotic figures [9]. Our case showed some of these features of proliferating pilomatrixoma, but the size was not in keeping with the original description of a proliferating lesion.

Differential diagnoses of these lesions of pilomatrixoma based on histological features include epidermal inclusion cyst, dermoid cyst, squamous cell carcinoma, basal cell carcinoma, some follicular neoplasms such as trichoblastoma, and giant cell lesions [10].

In conclusion, we report a case of a small lesion with concerning features for a pilomatrix carcinoma. The atypical features include focal infiltrating border, focal necrosis, and increase in mitotic activity. Given the focality of the changes, this lesion is best described as pilomatrixoma with atypical features, with wide excision recommended. Furthermore, our case may highlight the need to ensure close clinical follow-up for these lesions with unexpected atypical features for the concern of recurrence and malignant transformation.

\section{Statement of Ethics}

Written informed consent was obtained from the patient for participation and publication of this case report and accompanying images. A copy of this consent is with the corresponding author. The study was conducted according to the Declaration of Helsinki.

\section{Conflict of Interest Statement}

The authors declare no conflicts of interest or financial support.

\section{Karger' ${ }^{\prime \prime}$}




\section{Case Reports in Dermatology}

\section{Funding Sources}

There was no grant or funding support associated with this article.

\section{Author Contributions}

M. Missak drafted the manuscript, followed by critical revision and intellectual contributions by A. Haig and M. Gabril. M. Missak and M. Gabril prepared the histological images. All authors read and approved the final manuscript.

\section{References}

1 Forbis R Jr, Helwig EB. Pilomatrixoma (calcifying epithelioma). Arch Dermatol. 1961 Apr;83(4):606-18.

2 Berberian BJ, Colonna TM, Battaglia M, Sulica VI. Multiple pilomatricomas in association with myotonic dystrophy and a family history of melanoma. J Am Acad Dermatol. 1997 Aug;37(2 Pt 1):268-9.

3 Graham JL, Merwin CF. The tent sign of pilomatricoma. Cutis. 1978 Nov;22(5):577-80.

4 Julian CG, Bowers PW. A clinical review of 209 pilomatricomas. J Am Acad Dermatol. 1998 Aug;39(2 Pt 1): 191-5.

5 Inagaki A, Yamashita Y, Mori Y, Takeuchi E, Asaoka K, Murakami S. An unusual tumor of the ear: pilomatricoma in a middle-aged woman. Case Rep Otolaryngol. 2019 Dec;2019:4975216.

6 Pant I, Joshi SC, Kaur G, Kumar G. Pilomatricoma as a diagnostic pitfall in clinical practice: report of two cases and review of literature. Indian J Dermatol. 2010 Oct;55(4):390-2.

7 Sari A, Yavuzer R, Isik I, Latıfoğlu 0, Ataoğlu 0. Atypical presentation of pilomatricoma: a case report. Dermatol Surg. 2002 Jul;28(7):603-5.

8 Hardisson D, Linares MD, Cuevas-Santos J, Contreras F. Pilomatrix carcinoma: a clinicopathologic study of six cases and review of the literature. Am J Dermatopathol. 2001 Oct;23(5):394-401.

9 Kaddu S, Soyer HP, Wolf IH, Kerl H. Proliferating pilomatricoma. A histopathologic simulator of matrical carcinoma. J Cutan Pathol. 1997 Apr;24(4):228-34.

10 Prendes BL, Kangelaris GT, van Zante A, Wang SJ. Pilomatricoma masquerading as metastatic squamous cell carcinoma. Grand Rounds. 2012 Mar;12(1):17-22. 


\section{Case Reports in Dermatology}

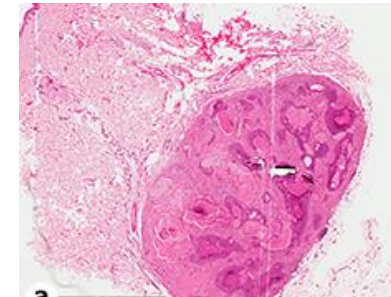

a

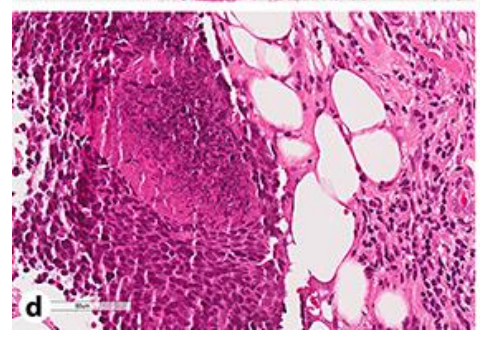

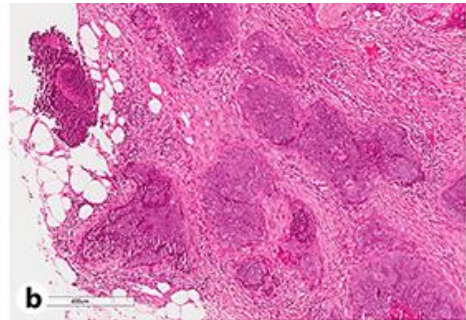

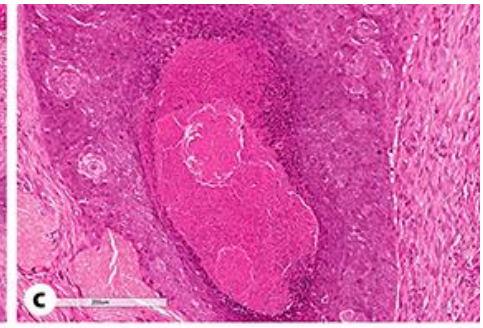

Fig. 1. Histological features of pilomatrixoma with atypical features. a Hematoxylin and eosin (H\&E) staining of paraffin-fixed tissue biopsy specimen viewed at $2 \times$ magnification. The tissue section demonstrates a nearly well-circumscribed dermal/subcutaneous nodule of basaloid cells and shadow cells. b H\&E higher $(10 \times)$ magnification of the tissue specimen showing focal infiltrating into subcutaneous fat at the periphery. c H\&E, 20× magnification highlights comedonecrosis. d H\&E, 20× magnification highlights cytological atypia and comedonecrosis. e H\&E, 40× magnification highlights increase in mitotic activity in the lesion. 